\title{
Evaluating the business value of RFID: Evidence from five case studies
}

\author{
Shiou-Fen Tzeng*, Wun-Hwa Chen, Fan-Yun Pai \\ Graduate Institute of Business Administration, National Taiwan University, No. 1, Sec. 4, Roosevelt Road, Taipei, Taiwan, ROC
}

Received 28 February 2006; accepted 25 February 2007

Available online 9 June 2007

\begin{abstract}
This paper presents an in-depth analysis toward understanding the business value components an organization can derive from adopting radio frequency identification (RFID). Although this subject is currently a hot topic, many organizations are slow in warming up to the idea of using RFID to conduct more effective and efficient business processes. We propose a framework for evaluating the business value of RFID technology, hoping that a better understanding of the business value of RFID will encourage more organizations to implement it. Emphasis is on delivering business value through refining business processes and expanding the business model. We illustrate these concepts drawing on the experience of five early adopters from the Taiwan healthcare industry and formulate this framework as a set of propositions based on relevant literature, cases from pioneers in the field and our intuition. These propositions will need to be validated through empirical evidence.
\end{abstract}

(C) 2007 Elsevier B.V. All rights reserved.

Keywords: Radio frequency identification (RFID); IT business value; Business process reengineering (BPR); U-healthcare

\section{Introduction}

Information technology (IT) is one of the most important resources in creating organizational value (Kohli and Devaraj, 2004) through its capability to transform the nature of products, processes, companies, industries and even competition itself (Porter and Millar, 1985). Owing to its "MOST" (mobility, organizational, systems and technologies) characteristics, radio frequency identification (RFID) has received considerable attention and is

\footnotetext{
*Corresponding author. Tel.: + 886233661048 ; fax: +886223625379 .

E-mail address: d90741004@ntu.edu.tw (S.-F. Tzeng).
}

considered to be the next wave of the IT revolution. An RFID can allow any tagged entity to be mobile, intelligent and communicate with an organization's overall information infrastructure (Curtin et al., 2007). Its applications are not a new phenomenon. The British Royal Air Force (RAF) used RFID-like technology in World War II to distinguish between enemy and friendly aircraft (Asif and Mandviwalla, 2005). Most recently, it is gaining importance and popularity in many areas such as marathon races, airline luggage tracking, electronic security keys, toll collection and asset tracking, etc. (Angeles, 2005; Ericson, 2004; Karkkainen, 2003; Srivastava, 2004) and is considered to be the next revolution in supply-chain management (Srivastava, 2004) and the healthcare industry (Ericson, 2004). 
The RFID is expected to add intelligence and capabilities to organizations by its identification, tracking and tracing nature. It can acquire a vast array of location and property information through entities that can be physically tagged and wirelessly scanned (Curtin et al., 2007; Weinstein, 2005). As the various entities associated with business processes become increasingly mobile in the presence of RFID, the ability of the organization to monitor the location, history and changing states of these tagged entities increases the level of process freedom (Keen and Mackintosh, 2001). The strategic importance of RFID applications cannot be underestimated. The rapid pace of adoption and advancement of RFID creates opportunities for new and innovative services provided through RFID infrastructures. The emergence of RFID is expected to drastically affect a number of industries and impact their strategic management (Curtin et al., 2007).

Both academics and practitioners are keenly aware how organizations can extract business value from RFID (Weinstein, 2005; Curtin et al., 2007). They include mechanical and electrical engineering (Glidden et al., 2004), systems and software engineering (Juels, 2004), health management (Thompson, 2004), marketing and customer relationship management (Compton, 2004). Among the questions being asked are how can our business integrate RFID into existing lines of business? How can we use RFID to reduce costs and increase competitiveness? How can RFID impact internal and external business processes? What are the new business opportunities enabled by RFID? This paper aims to develop a framework for evaluating the business value of RFID applications. The research question that underlies this study is "How should one evaluate the business value of RFID applications?" We will propose some research propositions based on our case studies. These propositions form the basic framework for further research into RFID applications.

Research to assess the strategic impact of RFID on organizations is scarce. This paper is a step towards filling this gap. It presents the results derived from case studies identifying the value of RFID in five healthcare organizations and shows how RFID can have a strategic impact and create business value. The research problems are as follows:

- How should enterprises evaluate the strategic implications of RFID applications?
- Present a framework for evaluating the business value of RFID applications.

The paper is organized as follows: Section 2 presents an overview of pertinent literature on RFID, IT business value and IT applications in the healthcare industry. Section 3 reports the research method. Five healthcare institutions are investigated in Section 4. Based upon our findings, we present seven propositions in Section 5. Finally, Section 6 presents our conclusions and some thoughts for future research.

\section{Relevant concepts from the literature}

The preliminary step in this research was to review four existing streams of research to gain an understanding of the source of value creation in RFID applications. These streams of research are RFID technology, IT business value, business process reengineering (BPR) and IT applications in the healthcare industry.

\subsection{Background on RFID}

RFID is an emerging technology intended to replace traditional barcodes in many ways (Asif and Mandviwalla, 2005; Chuang, 2005; DoIT, 2004a-c, Wang et al., 2005). Its wireless tracking nature allows a reader to activate a transponder on a radio frequency tag attached to, or embedded in, an item allowing the reader to remotely read and/or write data to the RFID tag (Das, 2002; ITAA, 2004; Want, 2004). It enables organizations to deliver value-added applications related to the tracking and intelligent management of any entity tagged with an RFID chip. The technology has been around for more than 50 years; however, it has not been widely used. Since 2003, when Wal-Mart announced its intention to introduce an RFID application, it has brought new business opportunities to many information companies (Chuang, 2005). With both identification and tracking characteristics, RFID may dramatically change an organization's capability to obtain real-time information about the location and properties of tagged object(s), such as people or products (Angeles, 2005; Karkkainen, 2003). Current research and development on RFID focus on the manufacturing and retail sectors to improve supply-chain efficiency and to learn more about consumer behavior. Healthcare is considered 
to be its next home (Chuang, 2005; DoIT, 2004a; Wang et al., 2005).

Although highly praised as the next wave of innovative technology, RFID is not yet widely accepted in practice. Based on a survey by the Advance e-Commerce Institute in Taiwan related to the RFID applications in Taiwan's Top 5000 enterprises, most enterprises are aware of RFID, but not ready to use it yet. Those who have a better understanding, or have read RFID-related documents, are in the logistics industry $(60 \%)$ and the healthcare industry $(33.3 \%)$. Only $8 \%$ of enterprises are currently using RFID-related applications. Most RFID applications are for warehouse management $(66.7 \%)$ and production processes $(33.3 \%)$. The survey shows that most enterprises do not have innovative RFID applications now in Taiwan (DoIT, 2005). It seems that most Taiwanese enterprises are still waiting for RFID applications.

\subsection{IT business value and $B P R$}

Tapscott and Caston (1993) argued that IT has become the most important enabler to enterprise activities including structure, operation and management. Topics of hot discussion are how IT will change the business process and if it will bring about the expected effects (Barua et al., 1995; Brynjolfsson and Hitt, 1996; Chan and Chung, 2002; Dewan and Kraemer, 1998; Gunasekaran and Nath, 1997; Lockamy and Smith, 1997; Melville et al., 2004). The relationship is not significant between IT investment and performance. Some studies show that more IT investment would yield a better performance, but other studies have opposite results (Barua et al., 1995; Bloch et al., 1996; Hitt and Brynjolfsson, 1996; Bharadwaj et al., 1999; Sircar et al., 2000).

With regard to productivity of IT or business performance, most of the studies measure the value by output results of business level, which merely provides limited understanding in terms of the value generated by IT (Mooney et al., 1996). Since the productivity factor cannot totally measure the benefits of IT, the best way to explore the effect of IT on the organization gradually transfers from an output-focus study to a process-oriented approach (Banker et al., 1990; Banker and Kauffman, 1991; Mooney et al., 1996). The critical factor for IT investment to achieve business value is the relationship between IT and process reengineering (Davenport and Short, 1990; Hammer and Champy, 1993;
Davenport, 1993). In brief, IT is treated as the trigger for process innovation. On the other hand, process innovation is regarded as a catalytic agent for the business value of IT resulting in higher productivity. In addition, IT business value and organizational business strategies are closely connected. However, IT itself cannot be responsible for the ultimate success or failure of enterprise strategies (Chan and Huff, 1993; Grabowski and Lee, 1993).

BPR can be defined as the fundamental reconsideration and radical redesign of organizational processes in order to achieve drastic improvement of current performance in cost, service and speed (Hammer and Champy, 1993). It is described as the fundamental rethinking and radical redesign of business processes to achieve dramatic improvements in critical, contemporary measures of performance, such as cost, quality, service and speed (Hammer and Stanton, 1999). BPR is not new. It has been around for some time. IT acquisition plays an important enabling role in most process reengineering projects (Davenport, 1993). Many proposed theories exist about BPR, such as MRP, MRPII, ERP and SCM.

Research in electronic data interchange (EDI) usage showed that integrating EDI with process redesign results is more benefits than EDI alone (Clark and Stoddard, 1996; Riggins and Mukhopadhyay, 1994). Similarly, RFID will require considerable process redesign at all stages in the value chain where the technology is applied (Chuang, 2005). The characteristics of RFID can make objects become intelligent and processes automatic. Thus, RFID can reduce the cost of collecting data on the front line and improve efficiency. As with other information systems, RFID is not simply a hardware or software purchase, but a tool. Unlike barcode systems, it is necessary to implement BPR with an innovative spirit on the fundamental processes before implementing RFID to achieve greater synergy. Similar to the implementations of ERP, some IT companies believe RFID systems will create competitiveness for enterprises after the ERP and SCM systems implementation (Guo, 2005).

\subsection{IT applications in the healthcare industry}

The Internet is one example of how technology applications continue to advance healthcare. How people give and receive health information, and the 
healthcare and E-commerce solutions that will penetrate all areas of healthcare are changing with the Internet. Many surveys indicate more customers are surfing the Internet to access healthcare information, services and advice on particular diseases, treatment regimens, or improving their own health management (HIMSS, 2003). Webenabled applications also improve medical practice by monitoring vital signs via devices to strengthen care delivery, improve communications between physician and patient, and support clinical decision and disease management using Internet solutions. Successful cases include cancer research, which creates a national database for the ease of monitoring cancer treatment and the sharing of new discoveries, and diabetic clinics, which create automatic diagnosis programmers (Rohm and Rohm, 2004). Another significant achievement is the extension and evolution of electronic health records.

In recent years, recognized shifts in information and communications technologies have taken place from the Internet to mobile computing. The major transformations, triggered by technological changes and convergences, introduced a new e-health innovative application-m-healthcare. m-Healthcare is defined by a range of mobile technologies applied to healthcare: wireless network infrastructure, mobile computing and handheld devices and mobile applications (Tessier, 2003). Predictably, $m$-healthcare has an enormous potential to greatly increase the volume of current e-healthcare applications (Smaling, 2003).

The ubiquitous computing revolution, which is considered an IT to fuse real space and cyberspace based on the networks among existing things in the real world, has been conducted over the whole of society (Watson, 2000; Watson et al., 2002). U-commerce, also referred to as "ubiquitous commerce", is a new paradigm that extends the Internet era by providing ubiquity, universality, uniqueness and unison (Accenture, 2002; GalanxhiJanaqi and Nash, 2004). RFID and the electronic product code network (EPCglobal) increase the ability to compare, identify, track and care for patients in hospitals. The healthcare industry will move from e- to u-healthcare. u-Healthcare is ubiquitous collecting of data, unique healthcare planning for every patient, universal caring for patients in either hospitals or homes and uniting of protecting patients from disease and doing physical rehabilitation. The RFID technology can facilitate the building of the u-healthcare environment, provide strategic services to patient-centered recording, use medical data for cooperative care, processintegrated decision support through current medical knowledge and comprehensively use patient data for research and healthcare reporting.

\section{Research methodology}

This research aims to study the strategic and organizational impacts of RFID technology. To date, most of the research on RFID has been focused on the description of its real-life applications in various settings; however not much research on the theoretical framework has been proposed. Hence, we adopt the case research approach to exploit a new theoretical framework. A case study is an "empirical inquiry that investigates a contemporary phenomenon within its real-life context, especially where the boundaries between the phenomenon and context are not clearly evidenced" (Yin, 1994). Case studies are a valuable tool for examining a contemporary phenomenon, especially one that is not clearly understood, asking how and why questions, and capturing the context.

In 2003, SARS caused panic across all Asian countries. Countries as far away as Canada were also infected. Thirty-seven patients died from SARS and some of the attending doctors and nurses were also infected with SARS in Taiwan. The outbreak of this serious disease left the safety of patients, doctors and nurses as a critical issue. Hence, under the supervision of the Department of Industrial Technology, Ministry of Economic Affairs in Taiwan (hereafter, DoIT), several hospitals were granted research funds to support the implementation of RFID to fight the potential spread of SARS. As requested by the advisory committee of the DoIT, each hospital is required to choose different healthcare improvement projects so that, as a whole, they will represent a complete picture of an all-RFID-ready hospital. Since then, the DoIT continued its support on RFID applications in the healthcare industry for other healthcare procedures so as to provide better and safer medical services to patients. In total, more than ten hospitals have already participated in this program. In this research, however, we only choose those hospitals that have already finished their projects so that the real impacts can be measured. Hence, all of the hospitals with completed projects are discussed here (see Table 1). 
Table 1

Key characteristics of the RFID applications studied

\begin{tabular}{|c|c|c|c|c|c|}
\hline & $\begin{array}{l}\text { Taipei Medical } \\
\text { University Hospital } \\
\text { (TMUH) }\end{array}$ & $\begin{array}{l}\text { Taipei Minicipal } \\
\text { WanFang Hospital } \\
(\text { WFH) }\end{array}$ & $\begin{array}{l}\text { En Chu Kong } \\
\text { Hospital (ECKH) }\end{array}$ & $\begin{array}{l}\text { Show Chawn } \\
\text { Memorial Hosptial } \\
(\mathrm{SCH})\end{array}$ & $\begin{array}{l}\text { Koo Foundation } \\
\text { Sun Yat-Sen Cancer } \\
\text { Center (KCC) }\end{array}$ \\
\hline \multirow[t]{2}{*}{ Project } & $\begin{array}{l}\text { Location-based } \\
\text { medicare service }\end{array}$ & $\begin{array}{l}\text { Wireless PDA \& } \\
\text { RFID system for } \\
\text { emergency room } \\
\text { observation }\end{array}$ & $\begin{array}{l}\text { RFID intelligent } \\
\text { healthcare platform }\end{array}$ & $\begin{array}{l}\text { Intelligent digital } \\
\text { health network }\end{array}$ & $\begin{array}{l}\text { Specialized } \\
\text { healthcare system }\end{array}$ \\
\hline & $\begin{array}{l}\text { RFID-based blood } \\
\text { bag and resource } \\
\text { management system }\end{array}$ & $\begin{array}{l}\text { Healthcare industry } \\
\text { RFID application } \\
\text { system }\end{array}$ & $\begin{array}{l}\text { Inpatient } \\
\text { management system }\end{array}$ & & \\
\hline Goal & SARS prevention & Patient safety & Sickroom safety & SARS prevention & SARS prevention \\
\hline Application & $\begin{array}{l}\text { SARS prevention } \\
\text { and isolation }\end{array}$ & $\begin{array}{l}\text { Emergency system } \\
\text { medicine inspection } \\
\text { and audit }\end{array}$ & $\begin{array}{l}\text { Inpatient } \\
\text { Management Waste } \\
\text { Management }\end{array}$ & $\begin{array}{l}\text { SARS Prevention } \\
\text { and Isolation } \\
\text { Healthcare Institute }\end{array}$ & $\begin{array}{l}\text { Entry and Exit } \\
\text { Control Exhibiting } \\
\text { SOP Management }\end{array}$ \\
\hline Start date & $2003 / 10$ & $2004 / 01$ & $2004 / 01$ & $2003 / 10$ & $2003 / 10$ \\
\hline Sponsor & $\begin{array}{l}\text { Ministry of } \\
\text { Economic Affairs }\end{array}$ & $\begin{array}{l}\text { Department of } \\
\text { Health }\end{array}$ & MOEA & MOEA & MOEA \\
\hline Implement & $\begin{array}{l}\text { Corporate with } \\
\text { NTU, III and PK } \\
\text { technology } \\
\text { Establish IT } \\
\text { consulting company }\end{array}$ & In house & Corporate with HP & Outsourcing & Outsourcing \\
\hline Outcome & Success & $\begin{array}{l}\text { Partial success } \\
\text { low usage in } \\
\text { emergency room }\end{array}$ & $\begin{array}{l}\text { Partial success } \\
\text { wireless technology } \\
\text { cannot use in surgery } \\
\text { room }\end{array}$ & Success & Success \\
\hline
\end{tabular}

As for the in-depth interviews, since one of the authors serves as the chief reviewer for the DoIT program, we were able to easily setup in-depth interviews with those involved in the RFID projects. The interview procedure was semi-structured to keep the structure of the interview open to allow interviewees to say what they wanted to share with us. During the interview, we recorded or wrote down interviewees' opinions. Each interview took around $1-2 \mathrm{~h}$ and, if deemed necessary, we used either e-mail or telephone to obtain more information from the subjects. Managers in the hospital were the main subjects of the interviews; they usually held positions as either the vice superintendent or the CIO of their hospitals. To increase the data reliability and depth, we also interviewed consultants (most from well-known companies such as Hewlett-Packard) who helped implement the RFID project, and the project managers and assistant managers of the companies in charge of system integration (see Table 2).

As for the field observation, throughout the 2-year implementation period, we conducted quarterly review meetings with each of the hospitals studied with most of the major decision makers and implementation team members attending the meetings. From time to time, we also conducted on-site visits to observe the utilization of the RFID system in real-life settings. The DoIT required all system and project-related documents to be kept for each meeting. Some other documents including the satisfaction survey of all stakeholders (i.e., patients, doctors and nurses) were also reviewed there.

To enhance the rigorousness of the study, we followed the principles of data collection proposed by Yin (1994):

- Use multiple sources of evidence. Multiple data sources can contribute to a high degree of construct validity. In our case study, we interviewed both nursing staff and project managers, who were provided with devices to support their activities and to enhance services. We also observed the nursing staff's use of such devices when they were interacting with customers. In addition, we used archival records such as annual reports and the company website to provide us with a more in-depth understanding of the organization, and to substantiate and complement the results of the study. 
Table 2

Interview subjects

\begin{tabular}{|c|c|c|c|}
\hline $\begin{array}{l}\text { Case } \\
\text { (hospital) }\end{array}$ & Position & $\begin{array}{l}\text { Their role } \\
\text { in RFID } \\
\text { Project }\end{array}$ & $\begin{array}{l}\text { Interview } \\
\text { date }\end{array}$ \\
\hline \multirow[t]{2}{*}{ TMUH } & Vice Information & $\begin{array}{l}\text { Project } \\
\text { Leader }\end{array}$ & $2005 / 03 / 04$ \\
\hline & Superintendent & & $2005 / 05 / 20$ \\
\hline WFH & $\begin{array}{l}\text { Vice } \\
\text { Superintendent } \\
\text { Vice Department } \\
\text { Director }\end{array}$ & $\begin{array}{l}\text { Project } \\
\text { Leader } \\
\text { Project } \\
\text { Manager }\end{array}$ & $2005 / 04 / 20$ \\
\hline ECKH & $\begin{array}{l}\text { Department } \\
\text { Director }\end{array}$ & $\begin{array}{l}\text { Project } \\
\text { Manager }\end{array}$ & $2006 / 07 / 19$ \\
\hline $\mathrm{SCH}$ & $\begin{array}{l}\text { Senior } \\
\text { Commissioner }\end{array}$ & $\begin{array}{l}\text { Project } \\
\text { Manager }\end{array}$ & $\begin{array}{l}2005 / 06 / 15 \\
2005 / 06 / 22\end{array}$ \\
\hline $\mathrm{KCC}$ & $\begin{array}{l}\text { Department } \\
\text { Director }\end{array}$ & $\begin{array}{l}\text { Project } \\
\text { Manager }\end{array}$ & $2005 / 07 / 07$ \\
\hline
\end{tabular}

- Creating a case study database. A case study database helps to increase the reliability of the case study (Yin, 1994). In our study, we maintained case study notes by taking notes during the interviews. We also audio recorded the interviews for documentation purposes. Our case study documents also included company background information and company annual reports.

\section{Case discussion and analysis}

The implementation of an RFID system for each case is described in this section, including case introduction and the process analysis for implementing RFID. This section ends with a summary, comparison and analysis of these cases.

\subsection{Introduction and discussion of the case studies}

\subsubsection{Taipei Medical University Hospital}

Established in 1967, Taipei Medical University Hospital (TMUH) is a 435-bed retrial medical care institution aimed at patient care, clinical teaching and medical research. In 2003, TMUH proposed a framework of "location-based medical service system (LBMS)" to track a patient's identification, path of motion and location to identify whether he/she was in close contact with infected patients out of the isolation area. If the system detected any event likely to violate the disease isolation policy, an alarm signal would immediately trigger and a related standard operating procedure (SOP) would be launched.

The main purpose for TMUH in implementing an RFID system was to monitor physiological signals and track the paths of infection sources to know with whom the infected patients had contact. Also, this system further combined GSM, GPRS, PHS and CDMA to trigger an alarm that initiated the SOP to prevent an epidemic spread of the disease and maintain the safety of healthcare personnel. The LBMS system was characterized as infrastructure like. The hospital expected to develop other applications based on this RFID system in addition to preventing the spread of SARS.

TMUH launched another RFID system in 2006, an RFID-based blood bag and resource management system. This system was based on LBMS to control blood bag circulation and take care of patient safety by integrating the hospital information system and healthcare industry experiments. Thus, the hospital constructed an "intelligent blood bag management system" and "secure move healthcare system" to meet the operational requirements of the Chinese Blood Donation Association. Meanwhile, "RFID-based platform system" was established to exchange-related information with other hospitals.

\subsubsection{Wan Fang Hospital}

Wan Fang Hospital (WFH) was the first buildoperate-transfer municipal hospital in Taipei. Established in 1989, it currently has 740 beds. In 2003, WFH proposed the "Wireless PDA \&amp;amp; RFID system for emergency room.' In past patient satisfaction surveys, the emergency room was always the area that performed the worst and had the most medical disputes. The RFID system was therefore first introduced to the emergency room. All patients that enter the emergency room are given a passive tag that stores the patient's ID number. Once a reader has been used to validate the patient's identity, it is used to access medical-related information downloaded through a PDA.

The main goal for WFH in implementing an RFID system was to improve treatment quality and patient satisfaction at the hospital. By making patient safety the starting point, the risk to patients posed by incorrect treatment, incorrect diagnosis 
and delays in treatment was reduced. Emergency room personnel are also able to confirm the identity of patients and know at all times their current phase of treatment. If improving patient identification can improve patient safety, then a reminder system for patients' physiological data can be used to monitor the patient's condition in real time.

In 2006, WFH launched another RFID systemHealthcare RFID application system. This drew mainly on the experience of the existing RFID system to develop a prototype system for medical auditing and the emergency medical system. Through the attempt to connect the intra- and extra-hospital systems, a full understanding was gained of how RFID could be applied to the medical treatment and care industry.

\subsubsection{Show Chwan Hospital}

Show Chawn Hospital ( $\mathrm{SCH}$ ) was established in 1973 and is now a regional hospital with 717 beds. In 2003, the SARS outbreak led to public panic, causing not only patient deaths, but also medical worker concerns. Protecting the lives of patients and medical workers therefore became the most critical issue. In response, $\mathrm{SCH}$ began looking at the possibility of "long-distance" and "non-contact" medical care models. SCH therefore collaborated with the Ministry of Economic Affairs' technology specialization initiative to establish an RFID project. Their goal was to build the "Intelligent digital health network." All RFID tags used at the $\mathrm{SCH}$ are the active type. Patient permission was requested in advance when fitted with the RFID tag.

The main goals for $\mathrm{SCH}$ in implementing an RFID system was to carry out patient temperature monitoring for potentially infectious patients who carried a fever, access control of workers, patient and medical worker tracking as well as tracking the movement of hospital waste in transport. The remote data link feature of RFID was also used at Changhua Senior Citizen Home. Since the senior citizen home has a shortage of care personnel at night, RFID can be used to transmit the physiological data and movements of bed ridden or handicapped patients to the $\mathrm{SCH}$ information system. The data can then be monitored at $\mathrm{SCH}$ and action taken if required.

\subsubsection{Koo Foundation Cancer Center}

Koo Foundation Cancer Center (KCC) was established in 1989 as a not-for-profit charity health organization. All administrative or medical decisions are based on the ideal of humanitarianism, with the patient's welfare being paramount. As a group, cancer patients have depressed immune systems making them more vulnerable to infection. KCC has always sought to introduce new technologies to improve their capability to control infectious diseases. During the SARS outbreak, for example, the center invested a great deal of manpower and resources in defending patients from the disease. KCC therefore participated in the Ministry of Economic Affairs' demonstration development project in hopes that the introduction of new IT technology would help improve the hospital's management capability. At KCC, its RFID applications focus on access control and drug dispensing SOPs. Hospital workers are equipped with active tags. In the future, this access control system will be expanded to include the entire hospital.

The main goal for KCC in implementing an RFID system was to be able to track the spread of infection and prevent its outbreak. RFID is therefore used to provide access control for people at the hospital to ensure a safer medical environment. Since the cancer patients at KCC use a complex variety of drugs, in the interest of improving patient safety, the drug dispensing process that previously used manual checks was revamped. The verification of patient identity and confirmation of the SOP reduces the risks from insufficient medical oversight.

\subsubsection{En Chu Kong Hospital}

En Chu Kong Hospital (ECKH) was established in 1973 and is today a regional teaching hospital with 501 beds. It follows the concept of "treating patients as our family members and honored guests" to provide high-quality medical service. While promoting a policy for mothers and their babies to share a room, it was discovered that many mothers were worried about the possibility of baby snatching from open hospital rooms. ECKH therefore sought a solution suitable for hospital room management and patient safety. In 2005, the "RFID smart medical platform" was applied to inpatient surgical safety management, infectious waste management, outpatient management and newborn management. Active RFID wrist tags were used for newborns, while passive wrist-tags were provided for inpatients.

The main goal for the ECKH in implementing an RFID system was to use technology to help the hospital redesign its SOP to provide patients with a more comprehensive set of silent protective 
measures. Through wireless communications and automatic scanning functions, the ECKH is now able to monitor and manage incidents without interfering with existing operations or requiring extra manpower.

\subsection{Synthesis}

Analyzing the information from these cases reveals the following common traits:

- Adoption of RFID results in a dramatic change both in the business processes and personnel of the organizations. The RFID-enabled reengineering exercise is intended to optimize and integrate business processes. Owing to the allocation change of human resources, estimation of the effectiveness of reengineering is not straightforward and is dependent on the analysis of many uncontrollable factors and the psychological climate of the organizations.

- Assessments of RFID applications are from both strategic and operational viewpoints. Strategic systems aim to improve customer satisfaction and new business opportunities. Operational systems focus on the efficiency and flexibility of process redesign. The evaluation of strategic systems has to be based on the perceived competitive impact, which is different from a cost based evaluation. An RFID systems are at the same time both strategic and operational in nature. Therefore, the evaluation has to be made from these two different perspectives.

- Implementation of RFID systems should consider stakeholders outside the organization's boundaries, including customers, suppliers and medical institutions in the value chain. To achieve the full potential of an RFID system, especially under collaborative structures such as cooperation between medical institutions, the evaluation should consider the impact of the RFID system on both internal and external stakeholders.

\section{An integrative framework of RFID business value creation}

The usage of RFID in hospitals is relatively new with very little reported empirical research. Therefore, we propose the value creation framework as a set of research propositions based on our case studies. With the ability to make objects more intelligent and automate processes, RFID helps to reduce the cost of collecting data and improve operational efficiency. The implementation of RFID is not just buying hardware and software; rather it requires the organization to undergo BPR with an innovative spirit in order to achieve the greatest synergy. Though beginning as a tool to achieve operational efficiency, some practitioners believe that RFID could become the next major weapon for organizations to gain strategic competitive advantage.

The integration of RFID technology and enterprise processes helps enterprises to develop better business models. It also leads to an effective supplychain system to coordinate upstream, downstream and to members overseas. Here, we analyze and summarize to identify strategic and organizational issues. Table 3 proposes the business value created by RFID applications.

Two major value categories are extracted from our case research. One is the refining of operational processes and the other is the extending of business boundaries and scope. Next, we propose in sequence several research propositions related to these two categories and provide support illustrations directly from our case study interviews.

\subsection{Research propositions}

Proposition 1. (Effective communications). Through improving data visibility and matching people and entities automatically, RFID can improve the effectiveness of communications among staff members.

It is a common practice for a hospital to establish standard operational procedures for each process to prevent mistakes when conducting medical treatments. However, sometimes ineffective communications and time pressures may cause errors. By the

Table 3

Components of the business value of RFID applications

\begin{tabular}{ll}
\hline Value created & Source \\
\hline Refine & $\begin{array}{l}\text { Effective communications } \\
\text { Increased asset utilization } \\
\text { Enhanced patient care process }\end{array}$ \\
& Active patient management \\
Extend & Virtual integration of the supply chain \\
& New service strategy \\
&
\end{tabular}


nature of RFID, relevant data can be read into the RFID system making it unnecessary for staff to key in data when monitored events occur. It also integrates current SOP so that it can detect abnormal events and promptly notify relevant staff (TMUH)

After introducing RFID, information systems can match patients with their own data. Thus, our staffs can maintain correct data through shift changes. It also prevents missing or incorrect data inherent in using oral communication (KCC).

An RFID provides identification functions by radio frequency. This characteristic leads RFID to continuously identify, locate and track patients and related medical devises at the right time and all the time. We employ RFID to increase the data visibility and improve the automation of data checking procedures between patient and entity. The reduction of double checking in the medical care services decreases the workload and resources needed in front line operations (WFH).

Proposition 2. (Increased asset utilization). Matched with a wireless networking system, RFID can improve the utilization of assets through the mobility, intelligence and communications capability of any tagged object.

Many hospitals lose equipment worth hundreds of thousands of dollars each year and spend countless hours searching for patient-care assets. This includes medical devices (such as infusion pumps, portable X-ray machines and patient monitoring devices) as well as other mobile assets (such as wheelchairs, stretchers and gurneys). Poor utilization and slow device cycle time mean that:

- many high-value assets go underutilized, while hospitals continue to overspend on new and rented assets,

- nurses must sacrifice patient-care time-finding equipment,

- maintenance staff loses productive hours searching for specific items that need maintenance.

The ability to find assets instantaneously and improve their flow through hospital processes saves staff time and lowers capital or lease costs (ECKH).

Using RFID tags for staffs, patients, medical instruments and patient records, the precise location of individual subjects can be tracked at all times, greatly reducing search times (TMUH).
After setting the clinical path for the patient's health treatment, our staffs can use the real-time monitoring system to discover the current utilization status of medical equipment and assets required by the patient allowing them to be effectively assigned, even in emergencies ( $\mathrm{SCH})$.

The use of RFID positioning, together with a wireless networking system, allows medical assets within the hospital to be inventoried from a fixed location. This can be extended to include asset use tracking, reducing the loss or misplacement of resources. Since RFID also allows data to be read and written, the use of scheduling algorithms enables up to date, optimal use of resource management. This improves the management efficiency of the medical asset inventory (WFH).

Through the complete and instantaneous wireless transmission of electronic data, our staff at the front end is freed from having to make repeated checks, writing reports and waiting for information to be conveyed. This allows them to devote more time to patient care. Using the wireless networking system to collate electronic patient records for storage, it also saves on time that would have otherwise been spent on paperwork after medical treatment. At the same time, it provides an effective method for confirming patient safety, ensuring timeliness of emergency medical treatment as well as reducing the loss of time and medical resources caused by the incomplete transmission of information (KCC).

Proposition 3. (Enhanced patient-care process). Through the intelligence built into systems and the extended availability of intelligent support systems, RFID technology can optimize the patient-care process.

RFID systems integrated with HIS systems can be used to record doctor and patient treatment times. The workload of medical staffs can be analyzed to optimize manpower allocation (ECKH).

When read-write-type tags worn by patients (containing important medical information such as the patient's basic information, drug allergies and patient records) are linked to the hospital's HIS system, our staffs have immediate access to key patient data, reducing the potential for an incorrect or delayed diagnosis $(\mathrm{SCH})$.

Emergency procedures are often very urgent and chaotic, so a reminder system is needed. By integrating RFID and HIS, the reminder system can alert our staffs to move on to the next patient as 
soon as possible. This will increase the satisfaction of patients and healthcare staff (WFH).

Direct and continuous access to identification, positioning and tracking functions for patients and their associated data can be provided through the use of RFID. This can be used to supplement existing medical care systems to track a patient's treatment, update data, provide patient status information and real-time monitoring, speed up the treatment and diagnosis process, ensure the reliability of medical treatment, provide an audit and confirmation mechanism to avoid medical mistakes and improve medical care quality (KCC).

The recording of medical treatments in patients' records is very important, but also very complicated. Since much of the data is very complicated, mistakes are relatively easy to make. Traditionally, incident reports and an audit of the records have been used to determine the root cause of the mistake and define an SOP. RFID can now be used to actively collect this data. If alerts have been triggered, then relevant personnel can be notified. This allows mistakes to be controlled before, or as, they can provide active and timely patient protection $(\mathrm{SCH})$.

To avoid the chance of error during medical treatment, an SOP is always defined. These procedures, however, may become flawed due to the urgency of the situation, a breakdown in communication or delays in the transmission of information. The use of RFID enables data to be collected immediately without the need for manual input, and is used along with the existing SOP to determine the current condition of the patient. When an incident occurs, relevant personnel can be automatically notified as well (TMUH).

Table 4 presents the patient-care process in ECKH.

Proposition 4. (Active Patient Management). An RFID can transform the pattern of traditional healthcare by allowing the patient to participate actively in their treatment process, enabling them to initiate each medical treatment item and provide a mechanism for them to query their treatment information at any time.

When using RFID to initiate a treatment, the tag is supplied with key information or process-related management data. Patients can use an HIS kiosk system located in each section to read their own records. This allows patients to know their current health status and progress $(\mathrm{ECKH})$.
Table 4

Patient care process in En Chu Kong Hospital

\begin{tabular}{|c|c|c|c|}
\hline Process & As-Is & RFID application & Difference \\
\hline $\begin{array}{l}\text { SOP } \\
\text { compliance }\end{array}$ & Manual & Auto evidence & $\begin{array}{l}100 \% \text { enforcement } \\
\text { with auto time stamp } \\
\text { and proof of action }\end{array}$ \\
\hline \multirow[t]{2}{*}{ Data entry } & Manual & $\begin{array}{l}\text { RFID auto } \\
\text { verification }\end{array}$ & Avoid mistakes \\
\hline & & & Rea-time alert \\
\hline $\begin{array}{l}\text { Wristband } \\
\text { preparation }\end{array}$ & $\begin{array}{l}\text { Manual } \\
\text { with } \\
\text { name } \\
\text { only }\end{array}$ & $\begin{array}{l}\text { Auto printed with } \\
\text { visible and } \\
\text { invisible } \\
\text { information }\end{array}$ & $\begin{array}{l}\text { Avoid human } \\
\text { mistakes and has more } \\
\text { integrated data }\end{array}$ \\
\hline Integration & $\begin{array}{l}\text { Manual } \\
\text { control }\end{array}$ & $\begin{array}{l}\text { Auto trigger- } \\
\text { related necessary } \\
\text { processes }\end{array}$ & $\begin{array}{l}\text { Simplified and } \\
\text { integrated operation } \\
\text { accuracy }\end{array}$ \\
\hline $\begin{array}{l}\text { Patient } \\
\text { status } \\
\text { display }\end{array}$ & $\begin{array}{l}\text { Manual } \\
\text { entry }\end{array}$ & $\begin{array}{l}\text { Auto status } \\
\text { change }\end{array}$ & Real-time accuracy \\
\hline
\end{tabular}

Patients can also find out where they are on a testing schedule (for example, how many people to go before it is their turn) and therefore better arrange their free time (TMUH).

When RFID and wireless technology is introduced at a hospital, it removes constraints on the transmission of information and a patient's physiological data can be actively uploaded in real time. After being processed through various alert systems, it provides healthcare staffs with a real-time view of patient data. Thus, healthcare can improve management effectiveness by moving away from the generation of reports and passive management to rely more on benchmark setting and automatic alerts (KCC).

Proposition 5. (Virtual integration of the supply chain). An RFID technology can virtually integrate information/resource sharing across the supply chain by improving the visibility of data during workflow, the capability to collect information and by spanning a variety of organizational environments and business processes.

To increase the effective utilization of resources, Taiwan's medical organizations have gradually become horizontally integrated or have created regional strategic alliances of medical institutions. Hospitals sharing medical information and data could reduce the amount of resources spent on redundant checks and allow the savings to become hospital profits. RFID applications can provide this capability $(\mathrm{SCH})$. 
Emergency medical services are highly reliant on inter-hospital cooperation. Using RFID to integrate emergency medical logistics (patient) and information flow (patient record), all of the data in the emergency medical supply chain can be linked together to create an optimized emergency medical operations model; thus, resolving the problem of incompatible patient information and medical data flows that exist between the responsible hospital, fire department, health bureau and dispatch center. At the operational level, RFID can be used to implement categorized pre-arrival treatment so that health resources and scheduling can be optimized by the time a patient reaches the hospital's emergency room. On the management level, when a major disaster occurs this will provide an improved exchange of information and communication between the responsible hospital, local fire department and the health bureau reducing the information asymmetry between them. At the strategic level, it enables a region's patient information and distribution to be reported fully, allowing resources to be assigned and organized as necessary (WFH).

The medical institution currently uses a lot of manpower and paperwork to carry out batch management. In such a system, drugs and medical equipment cannot be tracked individually. In a test trial of RFID applied to the drug and blood supply chain in this project, cooperation across companies and between units was achieved along with individual tracking of product resumes (TMUH).

Proposition 6. (New service strategy). Through RFID and the wireless sensor network environment established by EPCglobal, the meanings and constraints associated with location, space and time can be changed, so that RFID allows for new services to be created or existing services to be customized in innovative ways.

Using the RFID system to provide direct and continuous identification, position and tracking of patients, drugs and assets at the right time all the time, a standardized RFID software network architecture was used to convert the data gathered by RFID into information. This information was then processed by the back-end system into useful knowledge that could be used in the organization's decision-making process. Through the effective use of RFID and the EPCglobal network in medical institutions, (particularly for manpower intensive data operations such as search, input, collation and confirmation), not only can the risk of human medical oversight be significantly reduced, but the medical institution's treatment quality can also be effectively improved enhancing the hospital's operational efficiency and capability (TMUH).

The wireless sensor network environment created by RFID and EPCglobal demonstrated it would improve the level of care received by patients through the verification, identification and tracking of objects and people. In the future, medical organizations will move from "e-healthcare" towards "u-healthcare" - all aspect collection and monitoring (ubiquitous), personalized medical and health promotion planning after identification (unique), complete care at home and at the hospital for the entire person (universal) as well as a healthcare system that combines prevention, treatment and rehabilitation (united). The use of RFID will contribute to the creation of this " $u$-healthcare" concept to provide patients with a complete medical environment. In the medical industry, RFID can be applied to a hospital's internal management and external supply-chain management to create a total healthcare environment, significantly changing the nature of the entire healthcare industry and bringing about a new approach in healthcare management (TMUH).

Proposition 7. (New business opportunities). The implementation of RFID provides sources of value through new business opportunities.

An RFID is expected to replace the currently widespread use of barcode scanning systems. It has a broad range of applications, from passing through customs during travel and logistics management in the manufacturing industry, to every step of medical pharmaceuticals management. Case studies presented here indicate that RFID, when applied to the medical industry, can create a completely new operational model. This new model has potential to benefit both hospitals and patients while saving manpower, time and cost. The precision of RFID data processing will also help to ensure that patient data is properly verified. At the hospitals involved in the case studies, continued technological innovations and operational process improvements were made during the RFID systems' introduction. A comprehensive exchange platform and supervisory mechanism was also provided during the execution of the project through the creation of an incubation center. The experience and knowledge from these successful implementations can be packaged into duplicable modules. Through the 
incubation center, these experiences can be reproduced at other organizations that wish to introduce RFID. This will provide the medical services industry additional areas to improve upon as well as introduce a new business opportunity to the hospitals involved (WFH).

\section{Conclusion}

Although RFID is now considered to be a new technology application with the potential for explosive long-term growth, RFID applications are still in their infancy with their contributions to enterprises still unproven. Though everyone has great expectations for this new technology, it has not yet achieved widespread acceptance. RFID, of course, has a great deal of potential in business automation. It is particularly useful for rectifying inefficiencies in workflow. This study uses hospitals where RFID applications have been introduced as a case study to provide a framework for businesses to see how RFID applications can create business value. The model shows that for RFID to truly demonstrate its commercial value, the new technology must be integrated into existing business systems. It must also be included within the overall business framework with respect to issues such as workflow, supply-chain relationships and leveraging of business capabilities.

This research was carried out in the healthcare service industry in Taiwan, but there is no reason to suppose that the same approach cannot be applied for RFID applications in other industries. The applied results can be insightful to the business value of RFID from both the processes and business opportunities viewpoints. Also, future empirical and conceptual research will be helpful in refining and validating our propositions, and will become possible when a sufficient number of experiences are collected and studied.

\section{Acknowledgments}

We would like to thank two anonymous referees and the editor, Dr. Fred Riggins for valuable suggestions.

\section{References}

Accenture Inc., 2002. Seize the day: The silent commerce imperative, USA.
Angeles, R., 2005. RFID technology: Supply-chain applications and implementations issues. Information Systems Management 22 (1), 51-65.

Asif, Z., Mandviwalla, M., 2005. Integrating the supply chain with RFID: A technical and business analysis. Communications of the Association for Information Systems 15 (24), 393-426.

Banker, R.D., Kauffman, R.J., 1991. Quantifying the business value of information technology: An illustration of the business value linkage framework. Working Paper, Stern School of Business, New York University.

Banker, R.D., Kauffamn, R.J., Morey, R.C., 1990. Measuring gains in operational efficiency from information technology: A study of the Positran development at Hardee's Inc. Journal of Management Information Systems 7 (2), 29-54.

Barua, A., Kriebel, C., Mukhopadhyay, T., 1995. Information technology and business value: An analytic and empirical investigation. Information Systems Research 6 (1), 3-23.

Bharadwaj, A., Bharadwaj, S., Konsynski, B.R., 1999. Information technology effects on firm performance as measured by Tobin's q. Management Science 45 (6), 1008-1024.

Bloch, M., Pigneur, Y., Segev, A., 1996. On the road of electronic commerce - A business value framework, gaining competitive advantage and some research issues. Available URL <http:// www.stern.nyu.edu/ mbloch/docs/roadtoec/ec.htm $\rangle$.

Brynjolfsson, E., Hitt, L., 1996. Paradox lost? Firm-level evidence on the returns to information systems spending. Management Science 42 (4), 541-558.

Chan, M.F.S., Chung, W.W.C., 2002. A framework to develop and enterprise information portal for contract manufacturing. International Journal of Production Economics 75 (1-2), 113-126.

Chan, Y.E., Huff, S., 1993. Strategic information systems alignment. Business Quarterly 58 (1), 263-276.

Chuang, Y.W., 2005. An exploration of application of radio frequency identification technology in hospitals. Working Paper, National Taiwan University.

Clark, T.H., Stoddard, D.B., 1996. Interorganizational business process redesign: Merging technological and process innovation. Journal of Management Information Systems 13 (2), 9-28.

Compton, J., 2004. RFID: Ready for industry deployment? CRM Magazine 8 (12), 12.

Curtin, J., Kauffman, R.J., Riggins, F.J., 2007. Making the "MOST" out of RFID technology: A research agenda for the study of the adoption, usage, and impact of RFID. Information Technology and Management 8 (2), 87-110.

Das, R., 2002. An Introduction to RFID and Tagging Technologies. Free IDTechEx White Paper, IDTechEx, Cambridge, UK. Available via http://www.idtechex.com.

Davenport, T.H., Short, J.E., 1990. The new industrial engineering-information technology and business process redesign. Sloan Management Review 31 (4), 11-27.

Davenport, T.H., 1993. Process Innovation Reengineering Work through Information Technology. Harvard Business School Press, Boston, MA.

Dewan, S., Kraemer, K.L., 1998. International dimensions of the productivity paradox. Communications of the ACM 41 (8), $56-62$.

DoIT, 2004a. Final Report of Location-Based Medicare Application. Department of Industrial Technology, Ministry of Economic Affairs, ROC. 
DoIT, 2004b. Final Report of RFID-Based Blood Bag and Resource Management System. Department of Industrial Technology, Ministry of Economic Affairs, ROC.

DoIT, 2004c. Final Report of Intelligent Digital Health Network. Department of Industrial Technology, Ministry of Economic Affairs, ROC.

DoIT, 2005. Final Report of RFID Intelligent Healthcare Platform. Department of Industrial Technology, Ministry of Economic Affairs, ROC.

Ericson, J., 2004. RFID for hospital care. The E-Business Executive Daily, July 23.

Galanxhi-Janaqi, H., Nash, F., 2004. U-Commerce: Emerging trends and research issues. Industrial Management and Data Systems 104 (9), 744-755.

Glidden, R., Bockorick, C., Cooper, S., Diorio, C., Dressler, D., Gutnik, V., et al., 2004. Design of ultra-cost UHF RFID tags for supply chain applications. IEEE Communications Magazine 42 (8), 140-151.

Grabowski, M., Lee, S., 1993. Linking information systems application portfolios and organizational strategy. In: Banker, R.D., Kauffman, R.J., Mahmood, M.A. (Eds.), Strategic Information Technology Management: Perspectives on Organizational Growth and Competitive Advantage. Idea Group Publishing, Harrisburg, PA.

Gunasekaran, A., Nath, B., 1997. The role of information technology in business process reengineering. International Journal of Production Economics 50 (2-3), 91-110.

Guo, C.H., 2005. The explore research for healthcare industry deploy RFID technology. Working Paper, National Chung Cheng University.

Hammer, M., Champy, J., 1993. Business Process Reengineering: A Manifesto for Business Revolution. Harper Business, New York, NY.

Hammer, M., Stanton, S., 1999. How process enterprises really work. Harvard Business Review 77 (6), 52-57.

Healthcare Information and Management Systems Society (HIMSS), 2003. HIMSS Patient Safety Survey.

Hitt, L., Brynjolfsson, E., 1996. Productivity, profitability and consumer surplus: Three different measures of information technology. MIS Quarterly 20, 121-142.

Information Technology Association of America (ITAA), 2004. Radio Frequency Identification: RFID ...Coming of Age. White Paper, Information Technology Association of America, Arlington, VA, June. Available on the Internet at http://www.itaa.org/rfid/docs/rfid.pdf.

Juels, A., 2004. RFID: Security and privacy for five-cent wireless devices. In: Proceedings of the 2004 ACM Workshop on Wireless Security, Philadelphia, PA. ACM Press, New York, p. 31 (abstract only).

Karkkainen, M., 2003. Increasing efficiency in the supply chain for short shelf life goods using RFID tagging. International Journal of Retail \& Distribution Management 31 (10), 529-536.

Keen, P.G., Mackintosh, R., 2001. The Freedom Economy: Gaining the M-Commerce Edge in the Era of the Wireless Internet. Osborne/McGraw-Hill, New York.

Kohli, R., Devaraj, S., 2004. Realizing the business value of information technology investment: An organizational process. MIS Quarterly Executive 3 (1), 53-68.
Lockamy, A., Smith, W.I., 1997. A strategic alignment approach for effective business process reengineering: Linking strategy, processes and customers for competitive advantage. International Journal of Production Economics 50, 141-153.

Melville, N., Kraemer, K., Gurbaxani, V., 2004. Review: Information technology and organizational performance: An integrative model of IT business value. MIS Quarterly 28 (2), 283-322.

Mooney, J.G., Gurbaxani, V., Kraemer, K.L., 1996. A process oriented framework for assessing the business value of information technology. The Database for Advances in Information Systems 27 (2), 68-81.

Porter, M.E., Millar, V.E., 1985. How information gives you competitive advantage. Harvard Business Review, 149-160.

Riggins, F.J., Mukhopadhyay, T., 1994. Interdependent benefits from interorganizational systems: Opportunities for business partner reengineering. Journal of Management Information Systems 11 (2), 37-57.

Rohm, B.W.T., Rohm Jr., C.E.T., 2004. Evolving medical informatics from diagnosis to prognosis. International Journal of Electronic Healthcare 1 (2), 103-111.

Sircar, S., Turnbow, J.L., Bordoloi, B., 2000. A framework for assessing the relationship between information technology investment and firm performance. Journal of Management Information Systems 16 (4), 69-97.

Smaling, J., 2003. The strategic view of wireless infrastructure. Health Management Technology 24 (11), 32.

Srivastava, B., 2004. Radio frequency ID technology: The next revolution in SCM. Business Horizons 47 (6), 60-68.

Tapscott, D., Caston, A., 1993. Paradigm Shift: The New Promise of Information Technology. McGraw-Hill, New York.

Tessier, C., 2003. Introduction to MoHCA and Mobile Health. Mobile Healthcare Alliance. URL: 〈http://www.mohca.org/ presentations/MoHCAintro0103.pdf $\rangle$.

Thompson, C.A., 2004. Radio frequency tags for identifying legitimate drug products discussed by tech industry. American Journal of Health-System Pharmacy 16 (14), 1430-1431.

Wang, S.W., Chen, W.H., Ong, C.S., Liu, L., Chuang, Y.W., 2005. RFID applications in hospitals: A case study on a demonstration RFID project in a Taiwan hospital. In: Sprauge, R. (Ed.), Proceedings of the 39th Hawaii International Conference on Systems Science, Kauai, HI, January 2006. IEEE Computer Society Press, Los Alamos, CA.

Want, R., 2004. Enabling ubiquitous sensing with RFID. Computer 37 (4), 84-86.

Watson, R.T., 2000. U-Commerce: The Ultimate. 〈http:// www.acm.org/ubiquity/views/r_watson_1.html $>$.

Watson, R.T., Pitt, L.F., Berthon, P., Zinkhan, G.M., 2002. U-Commerce: Extending the universe of marketing. Journal of Academy of Marketing Science 30 (4), 329-343.

Weinstein, D., 2005. RFID: A technical overview and its application to the enterprise. IT Professional, vol. 7(3). pp. 27-33.

Yin, R.K., 1994. Case Study Research: Design and MethodsApplied Social Research Methods. Sage Publications, Thousand Oaks, CA. 